\title{
A ECONOMIA DA ARBITRAGEM: ESCOLHA RACIONAL E GERAÇÃO DEVALOR
}

\author{
Antonio Celso Fonseca Pugliese e Bruno Meyerhof Salama
}

THE ECONOMICS OF ARBITRATION RATIONAL CHOICE AND VALUE CREATION

\section{RESUMO}

ESTE TEXTO ANALISA A ARBITRAGEM E SUAS RELAÇÕES COM A JURISDIÇÃO A PARTIR DO CONCEITO DE CUSTO DE TRANSAÇÃO. SEU OBJETIVO É MOSTRAR COMO A ARBITRAgEM É CAPAZ DE REDUZIR OS CUSTOS DE TRANSAÇÃO DE UM DETERMINADO AMBIENTE NORMATIVO E CONTRIBUIR PARA APERFEIÇOAR AS INSTITUIÇÕES. OS CUSTOS RELACIONADOS AO USO DA ARBITRAGEM E DA JURISDIÇÃO FUNCIONAM COMO UM PREÇO: QUANTO MAIOR O CUSTO, MENOR A PROCURA POR ELES (E VICEversal. Potencialmente, a arbitragem pode permitir a REDUÇÃO DOS CUSTOS DE TRANSAÇÃO EM RAZÃO (A) DA RELATIVA AGILIDADE COM QUE É CONCLUÍDA, (B) DA RELATIVA IMPARCIALIDADE DO ÁRBITRO E (C) DA ESPECIALIZAÇÃO DOS Árbitros. Além disso, a utilizaÇÃo da ARBitragem pode CRIAR MELHORES INCENTIVOS PARA O ADIMPLEMENTO DAS OBRIGAÇÕES CONTRATUAIS. ISSO PORQUE A INCLUSÃO DA CLÁUSULA ARBITRAL EM UM CONTRATO DÁ ÀS PARTES A POSSIBILIDADE DE REGULAR O AMBIENTE NORMATIVO A QUE SE SUBMETERÃO EM CASO DE DISPUTAS. A FALTA DE CLAREZA SOBRE A LEGALIDADE DOS PROCEDIMENTOS ARBITRAIS AUMENTA OS CUSTOS DE TRANSAÇÃO IMPOSTOS PELO AMBIENTE NORMATIVO. QUANTO MAIOR O GRAU DE INCERTEZA, TANTO MAIORES SERÃO OS INCENTIVOS PARA QUE OS INDIVÍDUOS ALTEREM SEUS PADRŌES NEGOCIAIS OU SIMPLESMENTE REDUZAM SUA PARTICIPAÇÃO EM ATIVIDADES ECONÔMICAS, REDUZINDO-SE, CONSEQÜENTEMENTE, O POTENCIAL DE GERAÇÃO DE RIQUEZA PARA A SOCIEDADE.

\section{PALAVRAS-CHAVE}

ARBITRAgEM, DIREITO E ECONOMIA, EFICIÊNCIA, SEGURANÇA JURÍDICA

\section{ABSTRACT}

THIS ARTICLE EXAMINES THE INSTITUTE OF ARBITRATION AND ITS RELATIONSHIP WITH COURT ACTIVITIES FROM THE PERSPECTIVE OF TRANSACTIONS COSTS. ITS OBJECTIVE IS TO SHOW HOW ARBITRATION CAN REDUCE THE TRANSACTIONS COSTS IN A CERTAIN NORMATIVE ENVIRONMENT AND CONTRIBUTE TO INSTITUTIONAL IMPROVEMENT. THE COSTS RELATED TO THE USE ARBITRATION AND COURT PROCEEDINGS WORK LIKE A PRICE MECHANISM: THE BIGGER THE COST, THE LOWER THE DEMAND (AND VICE-VERSA). THE INSTITUTE OF ARBITRATION CAN POTENTIALLY ENGENDER A REDUCTION OF TRANSACTIONS COSTS BECAUSE OF (A) THE RELATIVE QUICKNESS WITH WHICH IT IS CARRIED OUT, (B) THE RELATIVE NEUTRALITY OF ARBITERS, AND (C) THE SPECIALIZATION OF ARBITERS. MOREOVER, THE USE OF ARBITRATION CAN CREATE BETTER INCENTIVES FOR THE FULFILLMENT OF CONTRACTUAL PROMISES. THIS IS SO BECAUSE THE USE OF AN ARBITRATION CLAUSE IN A CONTRACT ALLOWS THE PARTIES TO REGULATE THE NORMATIVE ENVIRONMENT TO WHICH THEY WILL BE BOUND IN CASE OF A DISPUTE. THE LACK OF CLARITY ABOUT THE LAWFULNESS OF ARBITRATION PROCEEDINGS INCREASES THE TRANSACTIONS COSTS IMPOSED BY THE NORMATIVE FRAMEWORK. HIGHER LEVELS OF UNCERTAINTY CREATE INCENTIVES FOR THE INDIVIDUALS TO CHANGE THEIR NEGOTIATING PATTERNS OR SIMPLY TO REDUCE THEIR PARTICIPATION IN ECONOMIC ACTIVITIES, THEREBY REDUCING THE POTENTIAL FOR GENERATING WEALTH FOR SOCIETY.

\section{KEYWORDS}

ARBITRATION, LAW \& ECONOMICS, EFFICIENCY, LEGAL CERTAINTY 
"When will mankind be convinced and agree

to settle their difficulties by arbitration?"

Benjamin Franklin

\section{INTRODUÇÃO}

A prestação jurisdicional é função do Estado, visão partilhada até mesmo por teóricos liberais como Adam Smith (1976, p. 231) e Friedrich Hayek (1979, p. 47). Com isso, é fácil esquecer que a administração da Justiça e a própria arbitragem precedem a formação do Estado moderno e que, hoje em dia, parte importante da função jurisdicional é exercida por entes privados por meio de mecanismos alternativos de resolução de disputas (LANDES; POSNER, 1978), entre os quais se destaca a arbitragem.

Este artigo tem por objeto o exame de dois temas relacionados à arbitragem. O primeiro diz respeito aos motivos pelos quais indivíduos e empresas decidem arbitrar seus conflitos e o segundo, aos ganhos sociais que podem ser gerados pela utilização da arbitragem.

A perspectiva adotada será a da disciplina de Direito e Economia (também conhecida como "análise econômica do direito" ou simplesmente Law \& Economics). Em outro trabalho recente, Bruno Salama examinou em detalhes a epistemologia da disciplina de Direito e Economia (SALAMA, 2008). Aqui, traçamos os contornos de cinco de suas premissas metodológicas centrais: ${ }^{1}$

1. Escassez: os indivíduos vivem em um mundo de recursos escassos. Se os recursos fossem infinitos, não haveria o problema de ter que equacionar sua alocação; todos poderiam ter tudo o que quisessem e nas quantidades que quisessem, mas, em um mundo de recursos escassos, os indivíduos precisam realizar escolhas.

2. Maximização racional: os indivíduos farão escolhas que atendam seus interesses pessoais, sejam eles quais forem. Assim, na formulação de teorias, se partirá da premissa de que os indivíduos calculam para alcançar os maiores benefícios aos menores custos. Essa suposição de maximização racional leva ao chamado processo de “decisão marginalista". Isso quer dizer que, nos processos de tomada de decisão e realização de escolhas, os indivíduos realizarão a próxima unidade de uma dada atividade se, e somente se, os benefícios dessa próxima unidade excederem seus custos. ${ }^{2}$

3. Equilíbrio: o equilíbrio é o padrão comportamental interativo que se atinge quando todos os atores estão maximizando seus próprios interesses simultaneamente. Uma lei, por exemplo, é o resultado que surge - é um ponto de equilíbrio, portanto - 
quando todos os agentes políticos estão maximizam seus interesses por meio do processo político.

4. Incentivos: são preços implícitos. Nos mercados, indivíduos procuram maximizar seus benefícios realizando escolhas que minimizem seus custos e maximizem seus benefícios. Assim, consumidores geralmente irão consumir menor quantidade de um bem quando o preço subir e maior quantidade quando o preço cair. Já os produtores, geralmente, seguirão o caminho inverso (produzirão maior quantidade quando o preço subir e menor quantidade quando o preço cair). ${ }^{3}$ As condutas humanas, inseridas em um determinado contexto institucional, podem seguir uma dinâmica parecida. Por exemplo: de acordo com o Código Nacional de Trânsito, exceder o limite de velocidade em uma rodovia enseja o pagamento de multa. Portanto, ao dirigir um automóvel em alta velocidade, cada motorista irá sopesar, de um lado, (a) o benefício auferido com o aumento da velocidade (em virtude, por exemplo, do prazer de dirigir em alta velocidade ou do menor tempo do percurso) e, de outro, (b) o custo da multa por excesso de velocidade ponderado pela probabilidade de haver autuação e imposição da multa. Nesse caso específico, os incentivos legais resultam do limite de velocidade estabelecido em lei, do valor da multa e da eficácia da fiscalização.

5. Eficiência: o termo "eficiência" tem diversas acepções. Neste trabalho, eficiência diz respeito à maximização de ganhos e minimização de custos (SALAMA, 2008). ${ }^{4}$ Sob esta ótica, um processo será considerado eficiente se não for possível aumentar os benefícios sem também aumentar os custos. Para ilustrar o conceito, suponha que cada acidente aéreo cause, no total, custos de $\$ 100$ milhões (referimo-nos aqui à soma de todos os custos relevantes que englobam tanto as perdas da companhia aérea quanto as das vítimas dos acidentes). Uma empresa de transporte aéreo se depara com a decisão de investir ou não \$2 milhões em uma nova tecnologia de segurança aérea que causará uma diminuição de $1 \%$ na probabilidade de ocorrência de acidentes. Será que esse investimento é eficiente? A resposta é negativa. Afinal, a empresa investirá \$2 milhões para evitar custos de $\$ 1$ milhão ( $1 \%$ x $\$ 100$ milhões $=\$ 1$ milhão). O investimento nessa tecnologia diminui as chances de acidentes, mas torna a sociedade mais pobre e, por isso, não é eficiente.

Antes de prosseguir, convém perguntar: o que a justiça tem a ver com a eficiência? Neste trabalho, é possível apenas esboçar em poucas linhas os contornos de uma resposta minimamente satisfatória. A sugestão será a de que regras justas são, em geral, eficientes também. O desperdício de recursos é, no mínimo, indesejável, e há 
algo de intuitivo no emparelhamento entre eficiência (que corresponde à ausência de desperdício) e justiça.

Muitas das nossas intuições sobre noções de justiça podem ser igualmente explicadas sob a ótica da busca pela eficiência, e os exemplos vão desde "não roubarás até "a punição deve ser proporcional ao crime" (SALAMA, 2008), mas a discussão sobre o eficiente não substitui a discussão sobre o justo. Tomemos por exemplo a discussão a respeito dos custos de preservação de vidas humanas. Nenhuma sociedade, nem mesmo as mais desenvolvidas sociedades ocidentais, estão comprometidas com a preservação da vida a qualquer custo. Há muitas atividades (na verdade, a maioria delas) que, ao menos estatisticamente, certamente causarão a perda de vidas. Para ficarmos com o exemplo clássico de Guido Calabresi, "nós construímos um túnel sob o Mont Blanc porque isso é essencial para o mercado comum europeu e diminui o tempo de viagem de Roma a Paris, ainda que saibamos que aproximadamente um homem por quilômetro construído de túnel morrerá" (CALABRESI, 1970, p. 17-18).

A noção de que não estamos dispostos a preservar vidas a qualquer custo é tão perturbadora quanto realista. Aliás, a simples contratação pelo Estado de um policial que enfrenta o crime diariamente sugere que a sociedade está disposta a sacrificar algumas vidas (porque é certo que alguns policiais morrerão) para atingir alguma forma de paz social (e, no fim das contas, para evitar um número ainda maior de mortes).

Será que, sendo baixo o custo em vidas para a construção do túnel sob o Mont Blanc, a sociedade deve considerar justa a autorização de sua construção? Ou em termos mais abrangentes: será que tudo que é eficiente também é justo? Calabresi propôs como resposta um sonoro "não". A construção do direito sugere uma forma de ética pública, porque o direito está interligado com a justificação moral de ações tomadas no domínio público. Como nota Calabresi, "decisões que sopesem vidas humanas contra custos e conveniência não podem ser exclusivamente monetárias, de modo que a solução via mercado não é jamais a única a ser utilizada" (CALABRESI, 1970, p. 17-18).

Assim, a questão não é saber se eficiência pode ser igualada à justiça; não pode. A questão é saber como a construção da justiça pode se beneficiar da discussão de prós e contras, custos e benefícios e incentivos postos pelo sistema jurídico. A análise dos incentivos postos pela legislação é onde pode começar a discussão do justo; não onde ela deve acabar. Grandes dilemas morais se prestam à determinação política e devem ser decididos por meio dos sistemas políticos adotados pela sociedade. Contudo, noções de justiça - e construções jurídicas - que não levem em conta as prováveis conseqüências de suas articulações práticas são incompletas. O desafio é, portanto, enriquecer o debate jurídico integrando a discussão da eficiência na discussão do justo. 
Identificados os objetivos e premissas deste artigo, passaremos à análise crítica de alguns aspectos econômicos da utilização da arbitragem como meio de pacificação de conflitos sociais. Iniciaremos com a análise das razões econômicas que conduzem à adoção de cláusulas arbitrais, antes e depois do surgimento de controvérsias. A seguir, sustentaremos que a prestação jurisdicional privada compete com a prestação pública e que, no médio e longo prazos, esse processo pode conduzir ao aprimoramento dos sistemas públicos de prestação jurisdicional. Sugeriremos, então, que o enfraquecimento do instituto da arbitragem pode vir associado a conseqüências econômicas negativas e, finalmente, apresentaremos nossas conclusões.

\section{INCENTIVOS ECONÔMICOS DA ARBITRAGEM}

A literatura jurídico-econômica comparada ressalta duas principais razões para a adoção de cláusula arbitral nos contratos. ${ }^{5}$ Em primeiro lugar, a arbitragem poderá reduzir os custos de transação relacionados à prestação jurisdicional. Em segundo lugar, a arbitragem pode favorecer o estabelecimento de um sistema de incentivos mais adequado para o cumprimento de contratos, maximizando os ganhos na relação comercial entre as partes. Cada um desses dois aspectos é analisado a seguir.

\section{I REDUÇÃo DOS CUSTOS DE TRANSAÇÃO}

Custos de transação (ARROW, 1969) ${ }^{6}$ são os custos para realização de intercâmbios econômicos. Todos os custos que o indivíduo incorre, em função dos relacionamentos que deve manter com os demais integrantes do sistema produtivo, podem ser chamados de custos de transação. Assim, os custos de transação compreendem todos os custos associados a procura, negociação e monitoramento do intercâmbio econômico (inclusive os custos de oportunidade).

Um exemplo clássico de custos de transação diz respeito aos custos relacionados à solução de eventuais conflitos decorrentes de uma relação contratual. Quando analisa a conveniência e a oportunidade de celebração de um contrato, o indivíduo leva em consideração, entre outros fatores, os custos (a) de monitoramento do cumprimento do contrato pela outra parte (e.g., confirmação de pagamento das parcelas ou aferição da qualidade do produto prometido) e (b) a eficácia dos remédios oferecidos pela lei e pelo contrato para o caso de inadimplemento das obrigações assumidas. Quanto maiores os custos, menor o interesse do indivíduo em tomar parte no negócio jurídico.

Com efeito, se comparada à prestação jurisdicional estatal, a arbitragem pode reduzir os custos de transação da prestação jurisdicional. Em primeiro lugar, em razão da agilidade com que é concluída. O procedimento arbitral não está sujeito à rigidez dos processos judiciais, não se submete ao regime dos infindáveis recursos a instâncias superiores, e os árbitros, não raro, contam com a infra-estrutura necessária para que suas decisões sejam tomadas com grande rapidez. 
Na prestação jurisdicional estatal, o tempo de espera por uma decisão definitiva gera alto custo para as partes, que ficam privadas dos bens ou direitos litigiosos durante todos os anos que precedem o efetivo cumprimento da decisão transitada em julgado. Nesse caso, as partes arcam com o custo de oportunidade decorrente da privação dos bens e direitos disputados em Juízo. ${ }^{7}$

A possibilidade de melhora na qualidade das decisões, decorrente da especialização dos árbitros, também pode representar economia para as partes. Uma das vantagens da arbitragem é a possibilidade de utilização de árbitros que tenham familiaridade com a matéria objeto da controvérsia. Ao contrário do juiz estatal, o árbitro pode ter formação específica em área técnica que interessa diretamente ao objeto da arbitragem. É razoável supor, por exemplo, que o árbitro com anos de experiência na indústria petrolífera possa aferir com maior precisão os termos técnicos da contratação para exploração ou transporte de petróleo, além dos usos e costumes nos negócios da indústria petrolífera. A expectativa de que os contratos sejam interpretados por especialistas diminui os custos das partes relativos à negociação de contratos.

A especialização permite, assim, a redução dos erros nas decisões arbitrais. Em tese, apesar de todos os procedimentos estarem sujeitos a erros, a probabilidade de o árbitro especializado decidir de forma equivocada, por não conhecer a matéria discutida, é menor. A redução da probabilidade de erro na decisão reduz o risco da relação contratual, tornando o contrato mais atrativo para as partes e todo o mercado.

A diminuição de custos também pode ser reflexo de maior garantia de imparcialidade do árbitro. Em relações comerciais internacionais, por exemplo, existe temor de que as cortes estatais favoreçam a parte nacional em detrimento da parte estrangeira. A possibilidade de determinar, contratualmente, que a arbitragem ocorra em jurisdição estranha às partes faz com que cada uma delas retire de seus custos a parcela correspondente ao risco de litigar em ambiente jurídico desfavorável (BÜHRING-UHLE, 2005, p. 25). ${ }^{8}$

Portanto, as partes contratantes, ao preverem a arbitragem como forma de solução de controvérsias, antecipam que a expectativa de decisões mais ágeis e acertadas no futuro diminui o risco de comportamento oportunista no presente. As partes terão, assim, incentivos para cumprir as obrigações assumidas no contrato, pois eventuais inadimplementos serão punidos com rapidez e precisão. A maior confiabilidade dos contratos reduz os custos de transação (neste caso, representados pelo risco de a parte inadimplente beneficiar-se da morosidade dos procedimentos judiciais) e desonera a produção de riqueza social.

\section{i.2 Arbitragem eX ante facto e eX post facto}

Existem dois momentos em que os indivíduos podem optar pela arbitragem: antes ou depois do surgimento da disputa. Dá-se o nome de arbitragem ex ante facto ao 
acordo para realização de arbitragem celebrado "antes" do surgimento da disputa (notadamente, a negociação de cláusula arbitral) e, ao acordo para realização de arbitragem celebrado após o surgimento de controvérsias, dá-se o nome de arbitragem ex post facto.

A dinâmica do acordo para arbitragem ex ante facto e ex post facto obedece à mesma lógica econômica que tratamos neste estudo: indivíduos tendem a escolher a opção mais econômica, isto é, que minimize os custos e maximize os ganhos esperados.

Vimos na seção acima que a arbitragem pode ensejar a criação de valor de duas formas: reduzindo os custos de transação relacionados à prestação jurisdicional e incentivando as partes ao adimplemento contratual. Resta saber, agora, se essas economias ocorrem igualmente nas arbitragens ex ante facto e ex post facto. A resposta é negativa.

Após o surgimento da disputa, os custos com a prestação jurisdicional podem ser reduzidos, mas já não é possível maximizar os ganhos com incentivos para o adimplemento contratual. A razão é evidente: o surgimento da disputa pressupõe que uma parte não esteja satisfeita com a prestação da outra parte. Se a prestação defeituosa já ocorreu, já não há que falar em incentivos para adimplemento da obrigação.

A arbitragem ex ante facto é, portanto, capaz de gerar valor de mais maneiras do que a arbitragem ex post facto. A possibilidade de inclusão de cláusula arbitral em contrato confere às partes a possibilidade de regular o ambiente normativo a que se submeterão em caso de disputas. As partes podem optar pela arbitragem para reduzir os custos de disputas e coibir comportamentos oportunistas durante o curso do contrato. Após o surgimento da disputa, contudo, já não é possível alterar os incentivos do ambiente normativo (BOND, 1990). ${ }^{9}$

\section{COMPETIÇÃO PELA PRESTAÇÃO JURISDICIONAL E A EFICIÊNCIA DO ORDENAMENTO JURÍDICO}

A arbitragem pode ser entendida, do ponto de vista econômico, como a oferta de modelo de solução de controvérsias que compete com o modelo estatal de jurisdição. A competição pela atividade de prestação jurisdicional ocorre, assim, entre o prestador público - o Estado - e os árbitros e câmaras de arbitragem. A possibilidade de arbitrar conflitos obriga o indivíduo a escolher entre o processo judicial e o procedimento arbitral. ${ }^{10}$

A dinâmica da relação de oferta e procura pela prestação jurisdicional tem contornos semelhantes à da oferta e procura por produtos e serviços no mercado. A teoria microeconômica (e diversos casos práticos) indica que, nos mercados, a competição geralmente induz à redução dos preços.

Mas qual seria o "preço" pago pelos indivíduos pelos "serviços" de prestação jurisdicional pública e privada? ${ }^{11}$ Tanto no caso da jurisdição estatal quanto no caso 
da arbitragem, o "preço" corresponde aos custos de transação incorridos para a resolução da disputa (procedimentos lentos e ineficazes, por exemplo, significam maiores custos de transação para as partes e, portanto, "preços" mais elevados). ${ }^{12}$

A competição entre a prestação jurisdicional pública e privada induz, assim, a redução dos custos de transação associados à prestação jurisdicional pelo Estado. Em especial, a competição dá incentivos ao Estado para modernizar a legislação, repelindo normas indesejadas ou menos eficientes e substituindo-as por normas mais adequadas às necessidades da sociedade.

Não surpreende, portanto, que, no Brasil, o movimento de fortalecimento da arbitragem tenha sido acompanhado por seguidos esforços legislativos de recuperação da jurisdição estatal. ${ }^{13}$ Com efeito, diversos projetos de lei foram criados para aumentar a agilidade e a informalidade dos procedimentos judiciais (características típicas da arbitragem), como a implantação dos Juizados Especiais e as seguidas reformas da legislação processual civil. Apesar de os dois movimentos serem, em certa medida, uma reação conjunta às falhas do sistema judicial, não se pode negar que a evolução dos mecanismos de eficiência jurisdicional pode ser aproveitada por cada um deles.

A competição entre a prestação jurisdicional pública e privada contribui, assim, para a modernização legislativa e para a melhora do ambiente normativo e institucional. Nas palavras de Richard Posner, "quando as partes podem efetivamente estipular o foro, público ou privado, para resolverem disputas [...] a competição é factível e nós devemos esperar o surgimento de uma legislação substantiva mais eficiente" (LANDES; POSNER, 1978).

Essa assertiva é comprovada, de um ponto de vista histórico, pela absorção da Lex Mercatoria pelas diversas legislações comerciais dos Estados modernos. A Lex Mercatoria pode ser definida como corpo de normas criado por comerciantes na Idade Média a fim de atender às necessidades do renascimento comercial europeu. ${ }^{14}$ Esse sistema de normas surgiu como alternativa aos sistemas jurídicos que criavam entraves (ou elevados custos de transação) às relações comerciais da época, oferecendo aos agentes econômicos um sistema de solução de conflitos independente do Estado (GOLDMAN, 1964). ${ }^{15}$

Durante o movimento de codificação ocorrido na Europa continental no curso do século XIX, os principais conceitos da Lex Mercatoria foram incorporados às leis estatais e se tornaram fatores importantes para o sucesso dos movimentos de afirmação do Estado como eixo central de poder. ${ }^{16}$

Podemos afirmar, assim, que a competição incentiva os sistemas de prestação jurisdicional mais eficientes a inovar e os sistemas menos eficientes a emular. Ao longo do tempo, o aumento da competição entre a prestação jurisdicional pública e privada enseja alinhamento entre as políticas judiciais e as necessidades dos seus cidadãos. Nas palavras de Robert Cooter, "a competição enseja a evolução legal, [...] a inovação diferencia e a emulação harmoniza” (COOTER, 2000, p. 137). ${ }^{17}$ 


\section{Arbitragem e o COMportamento da Demanda POR SOLUÇÕES DE LITÍGIOS}

A arbitragem também pode ser analisada sob o ponto de vista da demanda, isto é, das forças de procura pela prestação jurisdicional. Vimos no capítulo anterior que o Estado, de um lado, e os árbitros e câmaras arbitrais, de outro, competem pela oferta dos "serviços" de prestação jurisdicional. Neste capítulo, enfocaremos a contrapartida da oferta, a demanda (ou procura).

No curso das discussões sobre a constitucionalidade da Lei da Arbitragem, muito se falou de suposta usurpação do poder jurisdicional do Estado. ${ }^{18}$ De modo geral, os defensores dessa tese acreditavam que, na impossibilidade de arbitrar conflitos, os indivíduos seriam compelidos a recorrer aos tribunais estatais para solução de seus litígios. A idéia, portanto, seria enfraquecer o instituto da arbitragem para preservar a demanda pela jurisdição do Estado.

Aqueles que se opuseram, exemplificativamente, à constitucionalidade da Lei de Arbitragem imaginavam que a eliminação do instituto potencialmente mais eficiente (arbitragem) garantiria a demanda pelo instituto menos eficiente (processo judicial). Esqueceram-se, contudo, de que os indivíduos optam, em regra, pela solução mais eficiente disponível no mercado.

Dessa forma, nos casos em que o indivíduo não possui incentivos para utilizar a arbitragem na solução de controvérsias, sua escolha pela jurisdição estatal dependerá da eficiência das instituições judiciais. Eventual falta de eficiência do Estado será um incentivo para que o indivíduo resolva suas disputas alterando seus padrões negociais, de forma a evitar ou tornar desnecessária a disputa judicial (LANDES; POSNER, 1978). É o caso, por exemplo, dos indivíduos que aumentam as taxas de juros e encargos em seus contratos, ou reduzem a oferta de crédito, para compensar a inadimplência esperada de seus clientes (PINHEIRO; SAADI, 2005), dos locadores que aumentam o valor do aluguel em razão da lentidão dos procedimentos para desocupação do imóvel ou mesmo daqueles que simplesmente reduzem ou eliminam sua participação em atividades de risco, ainda que essas atividades possuam relevante função social e potencial de geração de riqueza.

Fica evidente, dessa forma, que, em países como o Brasil, em que a prestação jurisdicional estatal é morosa e custosa, a criação de incertezas sobre a legalidade e a força vinculante dos procedimentos arbitrais não significará maior demanda pela tutela dos tribunais. Ao contrário, a demanda racional guiará os indivíduos a soluções extrajudiciais que minimizem os custos e maximizem os ganhos de suas relações jurídicas, fazendo com que toda a sociedade pague pela falta de eficiência do Estado. A falta de apoio do Estado à arbitragem, portanto, será causa para o aumento dos custos sociais, contrariando o interesse público de que as relações negociais sejam eficientes na produção de riquezas para a sociedade. 


\section{Conclusão}

A disciplina de Direito e Economia estuda a formação, estrutura, processos e impacto econômico da legislação e das instituições jurídico-políticas existentes (MERCURO; MEDEMA, 1999, p. 3). Na síntese de Susan Rose Ackerman, o Direito e Economia serviria para (a) definir a justificativa econômica da ação pública, (b) analisar de modo realista as instituições jurídicas e burocráticas e (c) definir papéis úteis para os tribunais dentro dos sistemas modernos de formulação de políticas públicas (ROSE-ACKERMAN, 1999, p. 79).

Normas jurídicas eficientes aumentam o potencial de produção de riqueza econômica pela sociedade e possibilitam que políticas públicas destinadas à geração de bem-estar social alcancem resultados mais eficazes e justos (CALABRESI, 1984, p. 833). ${ }^{19}$

Ao longo deste artigo, procuramos utilizar ferramentas da análise econômica do Direito para demonstrar que normas jurídicas que confiram legalidade e força vinculante à arbitragem são mais eficientes de um ponto de vista econômico. Nossos argumentos podem ser resumidos da seguinte forma:

(a) Ao resolverem disputas, tanto por meio da arbitragem quanto mediante procedimentos judiciais, as partes incorrem em custos de transação.

(b) Os custos de transação, associados à prestação jurisdicional (pública e privada), funcionam como preços: quanto maiores forem os preços, menor será a demanda (ou procura).

(c) A arbitragem permite redução dos custos de transação em virtude, principalmente, (a) da agilidade com que é concluída, (b) da especialização dos árbitros e (c) da imparcialidade do árbitro, especialmente nos casos de arbitragens internacionais.

(d) A maior eficiência da arbitragem na solução de disputas cria incentivos para o adimplemento das obrigações contratuais pelas partes.

(e) A inclusão de cláusula arbitral em contrato confere às partes a possibilidade de regular o ambiente normativo a que se submeterão em caso de disputas. A arbitragem ex ante facto tende, por este motivo, a gerar mais valor do que a arbitragem ex post facto.

(f) A arbitragem pode contribuir para o aperfeiçoamento do Estado e de institutos jurídicos concorrentes, como a legislação processual civil.

(g) Eventual questionamento ou insegurança jurídica sobre a legalidade dos procedimentos arbitrais aumenta os custos de transação impostos pelo ambiente normativo. 
Quanto maior o grau de incerteza, tanto maiores serão os incentivos para que indivíduos alterem seus padrões negociais ou simplesmente reduzam sua participação em atividades econômicas, reduzindo-se, conseqüentemente, a geração de riqueza social.

Em todo mundo, a jurisdição estatal tem sido desafiada por instrumentos alternativos de solução de litígios. A arbitragem vem, nesse contexto, se revelando como a melhor resposta para o desafio de uma prestação jurisdicional justa, rápida e eficiente.

: ARTIGo APROVAdo (12/05/2008) : RECEBIDO EM 23/01/2008

\section{NOTAS}

1 Um dos possíveis panos de fundo para análises empreendidas com a metodologia do Direito e Economia - a nosso juízo, o mais proveitoso - é a Teoria Neo-Institucionalista. Dela surgem pelo menos três idéias importantes: (a) o reconhecimento de que a Economia não tem existência independente ou dada, ou seja, de que a história importa, pois cria contextos culturais, sociais, políticos, jurídicos, etc. que tornam custosas, e às vezes inviáveis, mudanças radicais (o que se convencionou chamar de "dependência da trajetória", tradução de path dependence); (b) o reconhecimento de que a compreensão do Direito pressupõe uma análise evolucionista e centrada na diversidade e complexidade dos processos de mudança e ajuste (daí a importância da abertura para todas outras disciplinas além da Economia, mas também a utilidade da Teoria da Escolha Racional e da Teoria dos Jogos para estudar a complexidade dos processos de ação e decisão coletiva); e (c) a preocupação de ir além da filosofia prática e especulativa, visando à compreensão do mundo tal qual ele se apresenta (o que conduz ao estudo das práticas efetivamente observadas e do Direito tal qual de fato aplicado). Esses três pontos traduzem preocupações que o leitor deve ter em mente quando se ocupar da aplicação do ferramental econômico para a análise do direito.

2 A noção de maximização racional é instrumental. Ela serve para formular hipóteses e construir teorias que permitam simplificar, compreender e prever a conduta humana. A noção de racionalidade não significa que necessariamente há um cálculo consciente de custos de benefícios (embora esse cálculo freqüentemente ocorra, e qualquer advogado processualista sabe disso porque age estrategicamente no curso do processo). Mesmo assim, a pesquisa em Direito e Economia há muito tempo vem se afastando do paradigma da hiper-racionalidade, geralmente substituindo-o pela noção mais flexível de "racionalidade limitada". Reconhecendo que os indivíduos nem sempre processarão as informações disponíveis de forma ótima, eles passam a ser vistos como "intencionalmente racionais", ainda que limitados por aptidões cognitivas.

3 Para tornar a explicação mais simples, deixei de lado o problema da intensidade da resposta dos consumidores e produtores às mudanças de preço, isto é, das elasticidades.

4 Há outras duas acepções do termo "eficiência" que, neste texto, deixaremos de lado: a eficiência paretiana e a eficiência de Kaldor-Hicks.

5 As principais referências estrangeiras sobre o tema são as seguintes: SHAVELL, Steven. Alternative Dispute Resolution: An Economic Analysis. Journal of Legal Studies, v. 24, 1995; LANDES \& POSNER, op. cit.; SHAVELL, Steven. Suit, Settlement, and Trial: A Theoretical Analysis under Alternative Methods for the Allocation of Legal Costs. Journal of Legal Studies, v. 11, 1982; BERNSTEIN, Lisa. Opting Out of the Legal System: Extralegal Contractual Relations in the 
Diamond Industry. Journal of Legal Studies, v. 21, 1992, p. 115-157; BERNSTEIN, Lisa. Private Commercial Law in the Cotton Industry: Creating Cooperation through Rules, Norms, and Institutions. Michigan Law Review, v. 99, n. 7, p. 1724 1790, 2001; ASHENFELTER, Orley; BLOOM, David E. Models of Arbitrator Behavior: Theory and Evidence. The American Economic Review, v. 74, n. 1, 1984; BLOOM, David E. Empirical Models of Arbitrator Behavior under Conventional Arbitration. The Review of Economics and Statistics, v. 68, n. 4, 1986.

6 O conceito de custos de transação foi introduzido por Ronald Coase em 1937 com o famoso artigo The Nature of the Firm. Coase se referiu aos custos de transação como os "custos para a utilização dos mecanismos de preço". Essa conceituação reflete o fato de que qualquer interação econômica requer o uso (em maior ou menor grau) de recursos pelas partes. Kenneth Arrow definiu os custos de transação como "os custos para conduzir o sistema econômico".

7 O custo de oportunidade indica o valor do benefício abandonado ao se escolher uma alternativa em vez de outra. É, portanto, o custo de algo em termos de uma oportunidade renunciada ou impedida. Quanto mais longo o processo, maior o custo de oportunidade.

8 Entrevistas com 68 árbitros e advogados de diversos países com "grande experiência em disputas comerciais internacionais" indicou que as duas maiores vantagens do procedimento arbitral são "a neutralidade do foro arbitral" e a "possibilidade de adjudicação dos laudos arbitrais internacionais".

9 Não é por outra razão que a imensa maioria das arbitragens internacionais decorre de acordos ex ante facto.

10 Salvo as hipóteses em que o Estado detém o monopólio da prestação jurisdicional como nos casos de natureza criminal, eleitoral, etc.

11 Para levantamento empírico sobre o tema, vide: PINHEIRO, Armando Castelar. Magistrados, Judiciário e economia no Brasil. In: ZYLBERSTAJN, Décio; STAJN, Rachel. Direito \& economia: análise econômica do direito e das organizações. Rio de Janeiro: Elsevier, 2005. p. 244-283.

12 No caso brasileiro, por exemplo, a arbitragem somente passou a ser prática comum após 2001, com a decisão do STF no sentido da constitucionalidade da Lei da Arbitragem. Antes da decisão do STF, o risco de que o laudo arbitral não seria reconhecido pelo Judiciário representava um preço excessivamente alto a ser "pago" pelas partes na hipótese de realização de procedimento arbitral.

13 A legislação chinesa tem passado pelo mesmo fenômeno de competição e modernização com o crescimento e fortalecimento da arbitragem.

14 As principais características da lex mercatoria eram as seguintes: (a) caráter transnacional, (b) fundada nos usos e costumes do comércio, (c) aplicada por árbitros comerciantes, (d) informalidade e presteza e (e) realçada importância do princípio da boa-fé no desempenho da atividade mercantil.

15 Sobre o surgimento a partir da segunda metade do século XX do que supostamente seria uma "nova lex mercatoria”, vide: CARBONNEAU, Thomas E. Lex Mercatoria and Arbitration. Nova Iorque: Transnational Juris Publications, Dobbs Ferry, [s.d.].

16 Exemplos clássicos incluem o Code Commerce francês, de 1807, e o Handelgesetzbuch alemão, de 1897.

17 Naturalmente, a complexidade da evolução histórica torna falsa praticamente a totalidade das proposições universais sobre interações sociais. Isso vale também para as proposições de que a competição entre a prestação jurisdicional pública e privada sempre gera riqueza social, ou sempre beneficia o cidadão. Na falta de proposições universais satisfatórias, o cientista social se vê obrigado a fiar-se em generalizações.

18 Para uma discussão abrangente, sob o ponto de vista histórico, do crescimento da arbitragem em países da América Latina, vide: SIQUEIROS, José Luis. Arbitral Autonomy and National Sovereign Authority in Latin America. Lex Mercatoria and Arbitration. Editado por Thomas E. Carbonneau, Transnational Juris Publications, Inc., Dobbs Ferry, p. 183, [s.d.].

19 Nesse sentido, a análise econômica do Direito fornece instrumentos para que políticas em áreas como segurança, saúde, educação, combate à pobreza, entre tantas outras, sejam elaboradas com maior precisão pelos 
legisladores, implementadas com menores custos pelos governantes e interpretadas com mais subsídios por nossos tribunais. Embora a produção de riqueza não seja o único objetivo da ordem institucional, a produção de riqueza importa: não se pode, de boa-fé, advogar o desperdício de recursos, a não ser que circunstâncias excepcionais o justifiquem. Nas palavras de Guido Calabresi, “evitar desperdícios é parte de uma noção comum de justiça”.

\section{REFERÊNCIAS BIBLIOGRÁFICAS}

ARROW, Kenneth. The Organization of Economic Activity: Issues Pertinent to the Choice of Market versus NonMarket Allocation. The Analysis and Evaluation of Public Expenditures: The PBB-System, Joint Economic Committee, 91st Congress, 1st session, v. 1. Government Printing Office: Washington, D.C., 1969 BOND, Stephen. How to Draft an Arbitration Clause (Revisited). ICC International Court of Arbitration Bulletin, v. 1, 1990 BÜHRING-UHLE, Christian. A Survey on Arbitration and Settlement in International Business Disputes, parcialmente reproduzido. In: DRAHOZAL, Christopher; NAIMARK, Richard. Towards a Science of International Arbitration: Collected Empirical Research. The Hague: Kluwer Law International, 2005, p. 25

CALABRESI, Guido. First Party, Third Party and Product Liability Systems: Can Economic Analysis of Law Tell us Anything about Them?. Iowa Law Review, v. 69, 1984, p. 833

SMITH, Adam. The Wealth of Nations. [S.1.]: Edwin Cannan editor, v. 2, 1976, p. 231

. The Cost of Accidents: A Legal and Economic Analysis. New Haven:Yale University Press, 1970, p. 17-18

COOTER, Robert. The Strategic Constitution. Princeton: Princeton University Press, 2000, p. 137

GOLDMAN, Berthold. Frontières du Droit et Lex Mercatoria. Archives de Philosophie du Droit, v. 9, 1964

HAYEK, Friedrich. Law, Legislation and Liberty: The Political Order of a Free People. Chicago: The University Chicago Press, v. 3, 1979, p. 47

LANDES, William M.; POSNER, Richard A. Adjudication as a Private Good. Journal of Legal Studies, v. 8, 1979 MERCURO, Nicholas; MEDEMA, Steven G. Economics and the Law - From Posner to Post-Modernism, Princeton: Princeton University Press, 1999, p. 3

SALAMA, Bruno M. O que é Pesquisa em Direito e Economia?. In: Caderno Direito GV (no prelo). São Paulo: FGV/EDESP, 2008. Disponível em: <http://works.bepress.com/bruno_meyerhof_salama>.

PINHEIRO, Armando Castelar; SADDI, Jairo. Direito, economia e mercados. Rio de Janeiro: Elsevier, 2005, cap. 9 ROSE-ACKERMAN, Susan. Law and Economics: Paradigm, Politics, or Philosophy?, 1989, apud MERCURO, Nicholas e MEDEMA, Steven G. Economics and the Law - From Posner to Post-Modernism. Princeton: Princeton University Press, 1999 , p. 79

\section{Velloso, Pugliese \& Guidoni Advogados Rua São Tomé, 86 - 70 andar Vila Olímpia - 04551-080 São Paulo, Brasil puglieselavpgadvogados.com.br}

\section{Antonio Celso Fonseca Pugliese} Mestre em direito pela USP, Brasil
Árbitro da China International Economic and Trade
Arbitration Comission (CIETAC), em BeiJing, China
Visiting Scholar na Universidade de Columbia, EUA

\section{Bruno Meyerhof Salama}

DIREITO GV

Rua Rocha, 233 - $8^{\circ}$ andar Bela vista - 01330-000 São Paulo, Brasil bruno.salamalafgv.br
PROFESSOR DA DIREITO GV, BRASIL Doutor EM DIREITO PELA UC BERKELEY, EUA 